\title{
Natural History of Glamorgan
}

\section{Glamorgan County History}

Vol. 1 : Natural History. Edited by Prof. W. M. Tattersall. Pp. xix $+444+39$ plates. (Cardiff : William Lewis (Printers), Ltd., 1936). 25s. net.

$\mathrm{T}$ HIS handsome and well-produced volume is the first instalment of a projected history of the county of Glamorgan which was initiated in 1930 by the Lord Lieutenant of the County, the Earl of Plymouth. It is intended to cover the scientific interest of the county, and includes sections on the geology, climate and meteorology, soils, botany and zoology, written by voluntary workers, the whole being edited by Prof. W. M. Tattersall, professor of zoology and comparative anatomy in University College, Cardiff. This volume is to be followed by five others covering the industries, archæology, and ecclesiastical, political, economic and parochial history of Glamorgan. The scheme adopted is more or less that of the "Victoria County History", but the material of future volumes will be treated chronologically as a whole, and not as separate sections.

The first volume now published deals with the "natural environment of the county as a background to the history of man", and Prof. Tattersall is to be complimented upon setting a standard which, if followed in subsequent volumes, and in neighbouring counties, will result in an imposing contribution to the topographical history of Wales. In Glamorgan, the geological history has an important economic aspect owing to the material resources of the county, and this practical side is not forgotten in the biological sections, which include chapters on ornamental trees and shrubs under cultivation, and an account of the parasitic diseases to which cultivated plants and domesticated animals are subject.

In this connexion, attention may be specially directed to the section which discusses liver-rot in sheep. The distribution of four species of the primary host, Lymncea, has been plotted during a period of ten years, and also the areas in which $L$. truncatula, the only important species economically, does not occur. The conditions favourable and unfavourable to this species, and its methods of migration, have been investigated. Ecological research of this character has significant bearings on the incidence of an important epizootic disease. Similarly, the survey of the soils of the area, accompanied by soil maps, is a useful contribution to the solution of the problem of soil classification. The greater part of the history, however, is devoted to the fauna and flora of the district-the work of various specialists. Besides the usual lists of species, ecological and historical notes are included, which add considerably to the usefulness of the records. This section of the work is valuable as a first attempt to assemble in print the fauna and flora of the county, but an inspection of the lists suggests that considerable additions have still to be made to them.

The volume is beautifully printed and illustrated, and there is a good index. It is to be hoped that the reasonable price which the Committee has wisely decided to adopt will ensure a wide circulation for the series.

F. J. C.

\section{Another Dimension in Films}

\section{Colour Cinematography}

By Major Adrian Bernard Klein. Pp. xi $+350+29$ plates. (London: Chapman and Hall, Ltd., 1936.) 25s. net.

$\mathrm{N}^{\mathrm{or}}$ T all books are written by experts, in the sense that their authors know not only their special corner of their field but also what everyone else has done in that field and over a historical period of time. The present author complies with this definition for he gives valuable data respecting the system of colour cinematography in which he is most interested, and also collects and criticizes the entire range of systems and processes tried and developed up to date.

Major Klein is right in his contention that the release colour print must be used in standard projectors without any modification of the latter, beyond the obvious necessity of using specific carbons. It may never be assumed that the projectionist will carry out arbitrary instructions, precisely and time without number; such procedure will always break down and discredit the colour system. The remarkable freedom from breakdown in cinemas has been won by adhering to the limit of standardization. It follows that 